\title{
Japanese Teaching Mode Innovation on the Background of Big Data
}

\author{
Lijun Wu \\ College of Foreign Languages, Bohai University, Jinzhou, 121013, China \\ 176858309@qq.com
}

Keywords: college Japanese teaching; pragmatic competence cultivation; theoretical basis; composition on pragmatic competence; cultivating strategies

\begin{abstract}
The ultimate purpose of foreign language teaching is to cultivate the students' language communicative competence, pragmatic competence is an important part of communicative competence, college Japanese teaching and this paper study the pragmatic ability training related issues. First of all, studies the theoretical basis of pragmatic competence, including context theory, relevance theory and speech act theory; Then, this paper analyzes the pragmatic competence, including applied ability, reasoning ability, social ability of language and discourse analysis; Finally, put forward the pragmatic ability training strategy, develop the students' ability of autonomous learning, make full use of "listening, speaking, reading, writing and translation" and so on each teaching link, build Japanese import multimedia in the corpus, to strengthen the teaching of Japanese culture, strengthen the pragmatic awareness in the process of teaching.
\end{abstract}

\section{Introduction}

The Japanese majors in the institutions of higher learning stage teaching outline, points out that "the ultimate goal of foreign language teaching is to cultivate students with language communication ability". Pragmatic competence as an important part of communicative competence, should and language ability, runs through the whole process of Japanese teaching [1]. College students the opportunity to contact with Japanese and Japanese culture in daily life is very limited, is usually confined to the classroom teachers as the leading factor. So how to utmost to improve learners' pragmatic competence, teachers need to be consciously and targeted teaching activities. Although traditional foreign language teaching attention to the cultivation of students' language ability, but lack of students' language awareness and pragmatic consciousness and the cultivation of intercultural communication ability. Most of the current college Japanese course is given priority to with the traditional language teaching mode, focusing on the basic knowledge of Japanese language teaching, such as phonetics, vocabulary and grammar, the lack of practical teaching, the students master the basic knowledge of Japanese, but does not have a correct understanding of Japanese language, and flexible use of various communication occasions [2]. In Japanese teaching, the teacher should be combined with the actual situation, according to Japanese students' pragmatic level, aiming at how to teach the pragmatic knowledge and skills, and cultivate students' pragmatic competence and development to develop a scientific and effective teaching plan, at the same time, teachers should also be combined with the current Japanese teaching current situation of the development, actively explore more advanced teaching strategies, to teach students more rich and practical knowledge of pragmatics [3].

\section{Theoretical Basis on Pragmatic Competence}

Pragmatic competence research guided by the pragmatics, theoretical basis including three aspects:

(1) The context theory $[4,5]$. The connotations and characteristics of rich diversity, according to the context can be divided into the internal context and language external context. In language communication, both oral communication and written communication, language is inseparable from the internal context and external language context. Internal context refers to the language context, that is, the collocation of words, the choice of sentence, discourse structure and form inside information, such as sequence of words which, internal cohesion; Associated with verbal 
communication language external context refers to the social context and cultural context and situational context, it includes many factors: social and cultural background, social and political background, communication on both sides of the social psychological factors, social roles and communication on both sides of the encyclopedic knowledge, etc.

(2) The relevance theory. The nature of the relevance theory from the perspective of cognitive explanation communication, points out that the communication is clear-reasoning behavior. Cognitive context provides a means for pragmatic reasoning, and inference based on relevance principle and optimal relevance assumptions. Adaptation theory is that the process of language use is the process of language choice, is the process of all kinds of relationships with each other. Mode of relevance and adaptation theory framework and should be based on the relevance principle and optimal relevance assumptions, language context and communicative context with each other, make the relevance theory explanation and the adequacy of the adaptation theory to describe the adequacy of the unification. Relevance theory holds that communication is the essence of reasoning, the process of communication is a reasoning process. Therefore, people should from the perspective of communicative ability rather than behavior. The theory attempts to specify the information processing mechanism in the brain's role in the interpersonal communication, its category is that the brain mechanisms rather than language itself or language section process.

(3) The speech act theory. Speech act theory is that language is a means of conveying information, people are in words and deeds, all language including speech act. Language is a means of human communication, but the basic unit of human communication is not only a symbol, words, sentences, or the symbols, words, sentences of standard type, but to complete a certain behavior, such as: presentation, request, commands, questions, apologize, congratulations. Different behaviors can be expressed through the same kind of words and the same behavior can be realized through different words. Speech act theory emphasizes expressed by the speaker's words rather than the meaning of the meaning of language itself. Tend to be of significance on the study of a structure, the use of language and the function of the implication of the preset.

\section{Composition on Pragmatic Competence}

Pragmatic competence mainly include "Illocutionary competence, Inferential competence, Sociolinguistic competence and Discourse analysis competence", as shown in Fig. 1. The social language ability and the ability of discourse analysis are also belongs to the communication skills.

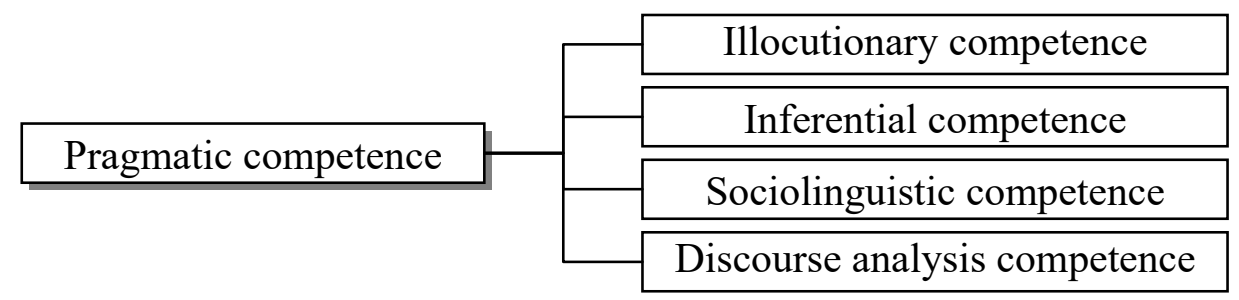

Fig. 1. Composition on pragmatic competence

(1) Illocutionary competence. Able to complete for the speech act of statements, called for, the communicator in expressing statement at the same time, also carried out some kind of behavior. Words speech act is in a typical for full implementation in speech ACTS. For the other is a positive statements, the subject is the speaker, for the verbs in the active voice, present tense. For sex and sexual speech ACTS is closely related, is always beyond the language communication behavior itself. For sexual speech act can be divided into specific statement, requests, promises and apology.

(2) Inferential competence. People use language is the process of a language based on the internal and external reasons, under the different levels of consciousness constantly to make the language selection process. Reasoning ability is an important ability to an understanding of daily communication. In many cases, for some reason, the communicator will not express views or opinions directly and this is where the combination of factors related to context, reasoning for words. In the teaching should pay attention to two points: one is that the cooperative principle 
combined with listening, speaking and writing teaching. Second, the relevance theory combined with reading and translation teaching.

(3) Sociolinguistic competence. Social language ability to cover in the context of different mastery of social cultural conventions, including all kinds of social factors involved, such as context, topic, social status, the discourse of harness of gender and age, etc. Specifically, social linguistic competence is the ability to explain the selected some social significance of language variants, to be able to use appropriate social language in communicative situations, and learn about communication context, including the role relationship, the Shared information of participants, communicative purpose, etc.[6]. Speakers in different communication situations need to use different words, or even show different values, beliefs and attitudes, social language ability is very important to social behavior.

(4) Discourse analysis of competence. Discourse analysis focuses on the differentiation of the discourse and dispersion, and drew attention from the overall correlation knowledge and rules to the knowledge rules of differentiation and diversity rules [7]. Discourse analysis to improve the pragmatic competence of enlightenment is as follows: to master the skill of discourse analysis, can make the conversation go smoothly; On the basis of the theory of discourse analysis can make the session more security; Discourse analysis can help to realize the communication of different communication object has a different style of discourse; Discourse analysis theory for some nonverbal communication also has a role in the interpretation of the behavior.

\section{Cultivating Strategies on Pragmatic Competence}

Pragmatic competence training is an important content of foreign language teaching, combining with the relevant theory of pragmatic competence and pragmatic competence, this paper puts forward the pragmatic ability training in college Japanese teaching strategies are as follows:

(1) Develop the students' ability of autonomous learning [8]. Autonomous learning is corresponding with the traditional accepting study a kind of modern learning style. Take the student as the main body of learning, the students themselves, not controlled by the others, undisturbed, through reading, listening, study, observation and practice means that individuals can get continuous change (knowledge and skills, the method and process, the improvement of emotion and value and sublimation) behavior. Autonomous learning can't as a simple way of instead of teaching, and should be considered an effective improve the teaching, increase the chance of language learning and to provide independent learning skills, make learners after completed formal course learning can continue to learn the language. Teachers teach students in Japanese knowledge in the process and should pay more attention to stimulate students' interest in learning Japanese, cultivate students' autonomous learning ability. Specific way can be: guide students to use online listening exercises on audiovisual material, guides the student to read online text materials, via E-mail, QQ, blogs and other network communication forms of exercise writing ability. Students can choose according to their interest in learning environment, adjust the content according to the requirements of their present form and the progress and realize the two-way interaction between media and students.

(2) Make full use of "listening, speaking, reading, writing and translation" and various teaching links [9]. Pragmatic knowledge of Japanese teaching in "listening, speaking, reading, writing and translating" each link using different methods, promoting the said to listen to, read presses to write, to write, to promote learning, and promote better improve students' pragmatic competence. In listening teaching, teachers should grasp the recessive teaching primarily, the principle of dominant class teaching is complementary, training college students to various contexts and the related expression of appropriateness and sensitivity. Students can't understand the literal meaning of the word, more words to use context information and resources for reasoning, so as to understand the meaning of the indirect expression; Reading comprehension is a process for associations, association selected properly, you will get the corresponding contextual effect, have the corresponding contextual effect, also can understand success. Teachers should require students to analyze the structure of the article, on the basis of according to the background knowledge, reading 
experience and language ability, speculated that the likelihood of events and development, an assertion of right and wrong, the final evaluation of paper quality; In translation classroom teaching activities, teachers should highlight is given priority to with explicit teaching characteristics, emphasizes the ways of understanding Chinese vocabulary, grammar, and used to express the similarities and differences, focusing on the sentence translation training, with long sentences or paragraphs writing as the auxiliary, cultivate students Chinese and Japanese thinking mode transformation.

(3) Construction of Japanese media corpus [10]. In the corpus is appeared in the actual use of language in real language materials, is based on the electronic computer as the carrier bearing of language knowledge resources, scientific sampling and processing of large-scale electronic text library. Movies and TV works by images, sounds and words such as a variety of media channels, in the story of topic full of interesting and sex, the image vividly show to the audience in the context of reality, the mother tongue if the specific situation of Japanese communication practice, greatly stimulate students' interest in learning. This profound experience as if, as it were, to break through the limitation of time and space, diversified introduction to Japanese social and cultural characteristics in various fields. Especially the main characteristics of multimedia media are to be able to appear in the process of communication in all aspects. This to the Japanese memory is more than stay in written, but the fragments of memory formation scenario. When encountered in the life similar context, students will quickly appear close to the native language if the natural response, paralanguage and language. Construction based on Japanese TV dramas, news documentaries and television talk shows as the context of multimedia project corpus, improve and make up for the lack of context in the environment problems in reality.

(4) Strengthen the input of culture in Japanese teaching. Language as a part of culture and is not only a kind of cultural phenomenon, but also the carrier of culture. Language is the human way of thinking and cultural exchange of one of the most main way, human way of thinking and cultural exchange is actually cultural formation and transmission performance, due to human thinking and in social practice, gradually created the culture, and is constantly spreading their ethnic culture in language communication $[11,12]$. The formation of the language limits cultural development. Deeply understand the relationship between language and culture relationship helps improve pragmatic competence, only by constantly to understand the culture of the target language countries or regions, can really grasp and use of a language. This cultural import method includes: teaching materials play an important role in the teaching process, is the basis of teaching goals, want to choose the original classic textbook; By reading literary works, newspapers, magazines or online reading, accumulate the Japanese cultural background, social customs, and social relations and related cultural knowledge materials; Using modern teaching means, give full play to the computer to text, graphics, images, animation, video, and audio etc. various media comprehensive processing capacity.

(5) Strengthen the pragmatic awareness in the process of teaching. Pragmatic consciousness refers to the changes of context in foreign language teaching to cultivate students to have the words change caused by the sensitivity. Awareness is the purpose of improving the students' pragmatic consciousness. Japanese teaching can not only impart some specific knowledge of speech ACTS, but also cultivate the students to use language because of the change of situation of the sensitivity of the words change. During Japanese teaching process should carry out the principle of "knowledge" and the "based on language for this" teaching to the "based on language use". In fact, pragmatic knowledge also depends on the specific context, Japanese teacher can't teach in class all use of speech ACTS. Therefore, improving the students' pragmatic consciousness can not only teach some simple pragmatic format, to compare two kinds of language pragmatic format, let the students understand the differences between the. In Japanese teaching, let students realize the differences in the implementation of speech act caused by the misunderstanding of the two languages, students are encouraged to use their common language in Japanese communication with knowledge, finally to teach in the implementation of the speech act may encounter when appropriate language form. 


\section{Conclusion}

Language is used in specific environment, depending on the environment, even the same kind of speech act can also adopt different ways of expression, which requires the language users have strong strain capacity and the strain capacity is pragmatic competence. Most of the expression of Japanese is euphemism and implicative, hidden implications, elusive. This is a Japanese learning difficulty. In a sense, pragmatic competence is the ability to use and make sense of a nonliteral language form [13]. As Japanese teacher, therefore, should pay attention to students' pragmatic competence training, introduce the related theories of pragmatics classroom and actively carry out effective language teaching. Teachers can teach students the language knowledge and pragmatic rules, definitely require learners to pay attention to a particular form, and the language rules are discussed and summarized.

\section{References}

[1] K. H. Guan, "0n the Cultivation of Japanese Pragmatics Teaching and Pragmatic Ability," Journal of Mudanjiang College of Education, vol. 31, no. 3, pp. 128-129, 2013.

[2] Y. J. Wei, M. Yu, "On the Cultivation of Pragmatic Competence of Business Japanese Students Under the New Economic Norm," Journal of Dalian University, vol. 36, no. 4, pp. 127-129, 2015.

[3] Y. F. Liu, "Research on pragmatic competence cultivation in business Japanese teaching," Journal of Jiamusi Vocational Institute, vol. 32, no. 12, pp. 290-291, 2015.

[4] Sina blog, "Context theory and its development," http://blog.sina.com.cn/s/blog_504ca8820100kkma.html, 2016-8-20.

[5] X. Wang, "The application of context theory in English reading in senior high school," Journal of Jiamusi Vocational Institute, vol. 33, no. 6, pp. 317, 2016.

[6] X. Xu, "On the cultivation of social language ability in foreign language teaching," Anhui Literature, vol. 54, no. 7, pp. 153-154, 2013.

[7] D. H. Ji, H. Y. Zeng, "Discourse analysis and communicative competence," The Border Economy and Culture, vol. 6, no. 2, pp. 104-105, 2009.

[8] S. R. Wang, "Cultivation of students' autonomous learning ability in Japanese by using network resources," Education for Chinese After-school, vol. 5, no. 24, pp. 96, 2011.

[9] Z. Y. Xu, "A Probe into the Ways to Improve English Pragmatic Competence of College Students," Theory and Practice of Education, vol. 34, no. 9, pp. 54-55, 2015.

[10] H. He, "The Research and Ponderation of The Cultivation Model of Students Pragmatic Competencein Japanese Teaching," Journal of Jilin Huaqiao University of Foreign Languages, vol. 12, no. 2, pp. 46-49, 2015.

[11] H. Y. Xiao, "On the importance of the introduction of Japanese teaching culture," The Science Education Article Collects, vol. 10, no. 6, pp. 141-143, 2013.

[12] Paper net, "A brief analysis of the relationship between language and culture," http://biyelunwen.yjbys.com/fanwen/yuyanwenxue/436400.html, 2016-8-10.

[13] China Paper Network, "On the cultivation of Applied Japanese talents from the perspective of pragmatic http://www.lunwencloud.com/lunwen/literature/yuyanwenzi/20150105/359725.html, 2016-8-20. 